\title{
Investigation of COVID-19 infection in subjects with Klinefelter syndrome
}

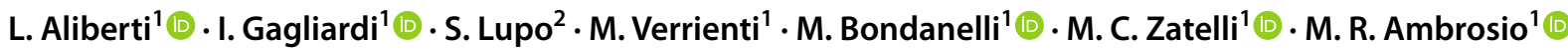

Received: 11 October 2021 / Accepted: 15 December 2021 / Published online: 22 January 2022

(C) Italian Society of Endocrinology (SIE) 2021

\begin{abstract}
Purpose COVID-19 has worse clinical outcomes in males compared with females and testosterone may determine gender differences. Hypogonadism and supernumerary X chromosome may have a role in the SARS-CoV-2 infection in Klinefelter syndrome (KS). Aim of the study was evaluating COVID-19 frequency and severity in KS.

Methods Participants were invited to complete a retrospective self-administered questionnaire containing multiple choice and open-ended answers.

Results COVID-19 was detected in 10\% of the evaluated KS subjects; none was hospitalized. $44.4 \%$ of COVID-19 patients had one cohabitant-infected versus $3 \%$ of non-infected $(p<0.01)$. Testosterone levels in infected patients were lower compared to those of non-infected subjects $(3.1 \pm 1.2 \mathrm{ng} / \mathrm{ml}$ vs. $5.2 \pm 2 \mathrm{ng} / \mathrm{ml}, p<0.05)$.

Conclusions The frequency of SARS-CoV-2 infection among KS subjects was $10 \%$. All infected patients showed mild symptoms. The presence of one affected cohabitant significantly associated with SARS-CoV-2 infection. An association between SARS-CoV-2 and hypogonadism was confirmed.
\end{abstract}

Keywords Klinefelter syndrome $\cdot$ COVID-19 $\cdot$ SARS-CoV-2 $\cdot$ Gender $\cdot$ Sex differences

\section{Background}

Available epidemiological data on COVID-19 show worse clinical outcomes in males as compared to females and testosterone has been suggested as the cause of gender differences [1]. This hypothesis is supported by the evidence that SARS-CoV-2 virus infects cells by binding to two host cellular proteins (ACE2 and TMPRSS2 protease) and that androgens could potentiate TMPRSS2 activity influencing viral entry into human cells [1]. Indeed, TMPRSS2 is regulated by both androgens and glucocorticoids in a lung-derived cell line model, but there are no studies in humans [2, 3]. Androgens can compromise antiviral immune response to SARS-CoV-2 because of an immune suppressive effect and immune response modulation [3]. In contrast, hospitalized

M. R. Ambrosio

mbrmrs@unife.it

1 Department of Medical Sciences, Section of Endocrinology and Internal Medicine, University of Ferrara, Via Ariosto 35, 44100 Ferrara, Italy

2 Endocrine Unit, Azienda Ospedaliero-Universitaria di Ferrara, Cona/Ferrara, Italy
COVID-19 men with a severe course of infection or entering Intensive Care Unit (ICU) have lower serum total testosterone at the time of hospitalization $[4,5]$. It has also been suggested that testes represent a "reservoir" for SARS-Cov-2, enhancing viral replication and causing worse outcome [5], based on the evidence that testicular cells express more ACE2 receptors as compared to ovaries [6]. Females, on the other hand, have greater natural immune response and a more vigorous response to most invading pathogens [1]. $\mathrm{X}$ chromosome contains genes related to immune regulation, suggesting that the number of female chromosomes could play a role in inflammation, influencing the production of inflammatory cytokines [1]. An increased production of inflammatory cytokines has been demonstrated in females and in patients with Klinefelter syndrome (KS) as compared to eugonadal males [1]. KS is characterized by hypergonadotropic hypogonadism, small testes, and infertility. Other features are dyslipidaemia, metabolic syndrome, increased visceral adiposity, predisposition to insulin resistance, and cardiovascular comorbidities [7]. The presence of hypogonadism, testicular atrophy, and the supernumerary $X$ chromosome may influence the development of SARSCoV-2 infection in KS subjects $[1,4]$. Our study is the first 
evaluating SARS-CoV-2 infection in KS subjects allowing gaining further information on the influence of hypogonadism and testosterone replacement therapy (TRT) in this infection.

\section{Purpose}

We aimed at evaluating the frequency of SARS-CoV-2 infection and the type and severity of COVID-19 symptoms developed in KS subjects. We also assessed whether the presence of hypogonadism or TRT may be related to the development of the infection and patient outcome.

\section{Methods}

KS individuals were recruited during Endocrine examinations or online through the help of the patients support Association "Nascere Klinefelter". Participants were invited to complete a retrospective self-administered and anonymous questionnaire containing multiple choice or open-ended answers. In case of KS patients $<18$ years of age, their parents could fill out the questionnaire. There was no compensation for the participants and the study was approved by the Local Ethic Committee. We subdivided patients in Group 1 (age $<14$ years), Group 2 (age 14-17 years), and Group 3 or adults (age $\geq 18$ years). The following data were collected: age, weight, height, pathological and pharmacological history, presence of smart working/distance learning, development of SARS-Cov-2 infection and period of infection, developed symptoms, type of infection management (at home or at hospital), and pharmacological treatment used in case of infection. The infected patients declared or showed a positive SARS-CoV-2 molecular nasopharyngeal swab. We do not have information concerning patients who were asymptomatic or who did not have any contact with infected subjects. In patients $<18$ years old, BMI was evaluated through sex-specific percentiles (pc) growth charts. We defined group 2-17 years of age as overweight if the BMI was $\geq 85$ th percentile but $<95$ th percentile for age and sex, as obese if the BMI was $\geq 95$ th percentile. We defined a child $<2$ year old obese if the sex-specific weight for recumbent length was $\geq 97.7$ th percentile. Testosterone levels and data on type/dose of testosterone replacement therapy were collected for group 2 and 3. In not-infected patients, we collected last follow-up testosterone levels and TRT type/dose (from March 2020 to June 2021). In case of SARS-CoV-2 infection, we investigated testosterone levels and data on TRT before the infection. Statistical analysis was performed by means of the Fisher's exact test for qualitative measures, by $T$ test for parametric distribution of quantitative measures and by Kruskal-Wallis test for non-parametric distribution of quantitative measures. $p$ values below 0.05 were considered to indicate statistical significance.

\section{Results}

A total of $120 \mathrm{KS}$ patients completed the survey. Mean age was $25.4 \pm 18.3$ years: 34 patients belonged to group 1 $(28.3 \%), 17$ to group $2(14.2 \%)$, and 69 to group $3(57.5 \%)$. Mean BMI percentile in group $1+2$ was $51.6 \pm 36.6 \mathrm{pc}$ (range 0.1-99 pc). Mean BMI in group 3 was $24.5 \pm 5.8 \mathrm{~kg} /$ $\mathrm{m}^{2}$ (range $14.1-42.4 \mathrm{~kg} / \mathrm{m}^{2}$ ). Participants came from Northern (80 patients: $66.7 \%$ ), Central (18 patients: $15 \%$ ), or Southern Italy (22 patients: 18.3\%). Among participants, 61 patients were on TRT due to primary hypogonadism $(50.8 \%)$ whereas 59 were not (49.2\%). Among 61 TRT users, 5 participants belonged to group $2(8.2 \%)$. Transdermal testosterone was used in $50.8 \%$ of cases, injectable testosterone undecanoate in $47.5 \%$ of cases, while only one patient used testosterone propionate (1.6\%).

Among participants, 12 developed SARS-CoV-2 infection (10\%) (Table 1). The median age of infected patients was slightly higher than that of non-infected subjects; there were no differences in BMI among COVID-19 and non-COVID-19 subjects (Table 2). Infection developed
Table 1 Frequency of SARSCoV-2 infection among KS patients and estimation of prevalence of SARS-CoV-2 infection among Italian males by Bassi et al. [8]

\begin{tabular}{lcll}
\hline $\begin{array}{l}\text { Age } \\
\text { (years) }\end{array}$ & $\begin{array}{l}\text { Estimated Italian prevalence in males } \\
\text { by Bassi et al. (\%) }\end{array}$ & $\begin{array}{l}\text { Estimated Italian } \\
\text { prevalence } \\
\text { in females by Bassi } \\
\text { et al. }(\%)\end{array}$ & $\begin{array}{l}\text { Frequency among KS: } \\
\mathrm{N}^{\circ} \text { COVID-19 KS } \\
\text { patients/N } \mathrm{N}^{\circ} \text { KS patients } \\
(\%)\end{array}$ \\
\hline $0-9$ & 8.54 & 6.85 & $2 / 28(7.14 \%)$ \\
$10-19$ & 7.59 & 7.04 & $3 / 32(9.4 \%)$ \\
$20-29$ & 8.17 & 9.94 & $3 / 12(25 \%)$ \\
$30-39$ & 9.08 & 10.45 & $1 / 15(6.7 \%)$ \\
$40-49$ & 8.86 & 11.49 & $0 / 16(0)$ \\
$50-59$ & 10.03 & 10.68 & $3 / 15(20 \%)$ \\
$60-69$ & 13.30 & 8.26 & $0 / 2(0)$ \\
Total & 9.91 & 9.92 & $12 / 120(10 \%)$ \\
\hline
\end{tabular}


Table 2 Characteristics of COVID-19 and non-COVID-19 patients

\begin{tabular}{|c|c|c|}
\hline & COVID-19 & Non-COVID-19 \\
\hline $\mathrm{KS}$ : patients $\mathrm{N}^{\circ}$ & 12 & 108 \\
\hline Group 1: patients $\mathrm{N}^{\circ}$ & 2 & 32 \\
\hline Group 2: patients $\mathrm{N}^{\circ}$ & 3 & 14 \\
\hline Group 3: patients $\mathrm{N}^{\circ}$ & 7 & 62 \\
\hline Age (years): median (IQ range) & $22.5(20.3)$ & $19(32)$ \\
\hline BMI (pc) group $1+2:$ Mean \pm DS (range) & $66.4 \pm 38.1(12-99)$ & $50.9 \pm 37.2(0.1-99)$ \\
\hline BMI $\left(\mathrm{Kg} / \mathrm{m}^{2}\right)$ group 3: Mean \pm DS (range) & $24.7 \pm 3.3(19.4-28.4)$ & $25.7 \pm 5.8(16.3-42.4)$ \\
\hline Northern Italy $\mathrm{N}^{\circ}(\%)$ & $7(58.3)$ & $73(67.6)$ \\
\hline Central Italy $\mathrm{N}^{\circ}(\%)$ & $3(25)$ & $15(13.9)$ \\
\hline Southern Italy $\mathrm{N}^{\circ}(\%)$ & $2(16.7)$ & $20(18.5)$ \\
\hline TRT: patients $\mathrm{N}^{\circ}(\%)$ & $7(58.3)$ & $54(50)$ \\
\hline TRT in group 2: patients $\mathrm{N}^{\circ}(\%)$ & $1 / 7(14.3)$ & $4 / 54(7.4)$ \\
\hline TRT in group 3: patients $\mathrm{N}^{\circ}(\%)$ & $6 / 7(85.7)$ & $50 / 54(92.6)$ \\
\hline Transdermal TRT: patients $\mathrm{N}^{\circ}(\%)$ & $4(57.1)$ & $27(50)$ \\
\hline Undecanoate $\mathrm{T}$ i.m.: patients $\mathrm{N}^{\circ}(\%)$ & $2(28.6)$ & $27(50)$ \\
\hline Propionate $\mathrm{T}$ : patients $\mathrm{N}^{\circ}(\%)$ & $1(14.3)$ & 0 \\
\hline Plasma testosterone (ng/ml): Mean DS (Range): & $3.1 \pm 1.2(1.5-4.6)^{*}$ & $5.2 \pm 2(2.6-11.5)^{*}$ \\
\hline Plasma testosterone group $2(\mathrm{ng} / \mathrm{ml}):$ Mean \pm DS (Range) & $2.2 \pm 0.6(1.5-2.6)$ & $4.9 \pm 2.7(2.97-10)$ \\
\hline Plasma testosterone group $3(\mathrm{ng} / \mathrm{ml})$ : Mean \pm DS (Range) & $3.5 \pm 0.9(2-4.6)^{+}$ & $5.2 \pm 2(2.6-11.5)^{+}$ \\
\hline Dyslipidemia group $2+3$ : patients $\mathrm{N}^{\circ}(\%)$ & $4 / 10(40)$ & $30 / 76(39.5)$ \\
\hline Hypertension group $2+3$ : patients $\mathrm{N}^{\circ}(\%)$ & $4 / 10(40)$ & $18 / 76(23.7)$ \\
\hline Epilepsy group $2+3$ : patients $\mathrm{N}^{\circ}(\%)$ & 0 & $5 / 76(6.6)$ \\
\hline DMT 2 group $2+3$ : patients $\mathrm{N}^{\circ}(\%)$ & $3 / 10(30)$ & $6 / 76(7.9)$ \\
\hline OSAS group $2+3$ : patients $\mathrm{N}^{\circ}(\%)$ & $3 / 10(30)^{+}$ & $5 / 76(6.6)^{+}$ \\
\hline Overweight/obesity group $1+2$ : patients $\mathrm{N}^{\circ}(\%)$ & $2(40) / 1(20)$ & $7(15.2) / 4(8.7)$ \\
\hline Overweight/obesity group 3: patients $\mathrm{N}^{\circ}(\%)$ & $5(71.4) * / 0$ & $11(17.7)^{*} / 17(27.4)$ \\
\hline
\end{tabular}

Group 1 subjects $<14$ years of age, Group 2 subjects 14-17 years of age, Group 3 subjects $\geq 18$ years of age, TRT Testosterone Replacement Therapy, $P c$ sex-specific percentiles, $I Q$ range interquartile range * or ${ }^{+}: p<0.05$ in March-April 2020 in 4 patients (33.3\%), in October-November 2020 in 4 patients (33.3\%), in and in January-May 2021 in 4 patients (33.3\%). SARS-CoV-2 infection was likely transmitted at home $(33.3 \%)$, at work (25\%), and at school (16.7\%), whereas 3 patients did not know how they were infected $(25 \%)$. The percentage of smart working/distance learning was similar in infected vs. non-infected KS subjects (42\% vs. $41.7 \%$, respectively), even though $19.4 \%$ of non-infected patients did not respond to this question. Considering only group 3 patients, the percentage of smart working/distance learning was lower in COVID-19 patients vs. non-COVID-19 patients ( $14 \%$ and $36 \%$, respectively, not significant); however, $26 \%$ of not-infected patients did not respond. All group 2 subjects attended school lessons at home by Internet. $44.4 \%$ of COVID-19 patients had at least one cohabitant-infected vs. $3 \%$ of not-infected patients $(p<0.01)$. The most reported symptoms were migraine $(33.3 \%)$, anosmia $(25 \%)$, and fever and respiratory symptoms $(16.7 \%)$, whereas gastrointestinal disorders, asthenia, and rhinitis occurred in $8.3 \%$ of cases. One patient did not develop any symptom (8.3\%). No one was hospitalized during infection nor used $\mathrm{O}_{2}$ therapy.

TRT was used in $58.3 \%$ of COVID-19 patients, whereas 54 non-infected subjects used TRT (50\%), with a not significant difference (Table 2). Testosterone formulations are summarized in Table 2. Among patients who tested testosterone levels (86/120), 70\% tested their testosterone levels at our Center, during a control visit. Our lab employs Chemiluminescence method. The remaining performed biochemical analysis in other laboratories. Mean testosterone levels in infected patients were significantly lower as compared to those of non-infected subjects $(3.1 \pm 1.2 \mathrm{ng} / \mathrm{ml}$ vs. $5.2 \pm 2 \mathrm{ng} /$ $\mathrm{ml} ; p<0.05)$. This difference was confirmed also considering COVID-19 and non-COVID-19 patients using TRT. Among KS patients using TRT, only 2 patients had testosterone levels $<2.3 \mathrm{ng} / \mathrm{ml}$ and they both developed COVID-19, whereas none of non-COVID-19 subjects had testosterone levels $<2.3 \mathrm{ng} / \mathrm{ml}$; this difference was statistically significant $(p<0.05)$. 
Comorbidities (hypertension, dyslipidemia, type 2 diabetes mellitus, and obstructive sleep apnea) were mostly present among COVID-19 patients as compared to nonCOVID-19 individuals (Table 2). Overweight (but not obesity) was significantly more present in COVID-19 adult group when compared with non-COVID KS adults $(p<0.05)$.

\section{Discussion}

In our study, SARS-Cov-2 infection was reported by $10 \%$ of KS patients. Higher frequency of infection was present among participant of 10-29 and 50-59 years of age. Bassi et al. reported that estimated prevalence in Italy was 9.92\% (9.91\% in males and $9.92 \%$ in females) with higher prevalence among older ages ( $\geq 50$ years) [8] (Table 1 ). In our study, only two patients were $\geq 60$ years old and this aspect may have influenced the results; indeed, KS patients aged $\geq 60$ years are less likely to use web tools to participate the survey. Moreover, a study performed in Washington State showed that SARS-CoV-2 infection is increasing among youngsters, maybe because their behavior disregards social distance and enhances attendance to social events [9]. This aspect may explain the higher SARS-CoV-2 infection rate among younger KS subjects.

The presence of at least one affected cohabitant was significantly associated with infection development. The percentage of smart working and distance learning among participants was slightly lower in infected as compared to non-infected subjects, suggesting a protective role for this aspect, but there was a percentage of not responders among non-infected patients that could have affected statistical significance.

All infected KS patients had mild symptoms, supporting the hypothesis that the presence of extra $\mathrm{X}$ chromosome and testicular atrophy (pathognomonic KS characteristic) may influence a better clinical outcome. Indeed, even though, in Italy, there was a slightly higher number of COVID-19 cases among females, they were less hospitalized, had delayed clinical presentation, and suffered from a less severe form of the disease [10]. The extra $X$ may influence immune genes expression, promoting CD4 + T-cell-mediated immune response [1].

KS patients who developed the infection had lower testosterone levels as compared to patients without infection and SARS-CoV-2 infection rate was slightly lower in adult patients using TRT as compared to adult KS individuals not TRT users. Even though the population involved in this analysis was largely on TRT, SARS-CoV-2 infection was more frequent among patients with insufficient testosterone supplementation. These data suggest that infected KS subjects with low compliance to TRT may also have low compliance to distancing measures and restrictions, exposing themselves to higher risk as compared to those who strictly followed medical (and social distance) instructions. Indeed, hospitalized COVID-19 men with a severe course of infection or entering in Intensive Care Unit (ICU) had lower serum total testosterone, but it was difficult to determine whether the low values were present before infection or developed during the acute phase $[4,5]$.

TRT formulation did not seem to influence the development of SARS-CoV-2 infection. Rambhatla et al. showed that TRT was not associated with a worse clinical outcome in men diagnosed with COVID-19 with similar hospitalization rate, thromboembolic events, and death [4].

A poor COVID-19 prognosis is associated with concomitant medical conditions such as hypertension and diabetes mellitus, and comorbidities that are observed in KS. In our population, the percentage of patients with diabetes, OSAS, dyslipidaemia, and hypertension was slightly higher in infected patients (in particular in older ages) supporting the association of these comorbidities with COVID-19.

Limits of our study are the use of a self-reported anonymous questionnaire and the small sample size of COVID-19 individuals. Moreover, in some cases, we did not have information about the assay used for testosterone measurement.

\section{Conclusions}

The frequency of SARS-Cov-2 infection among KS patients was $10 \%$. All infected patients had mild symptoms supporting the hypothesis that the presence of extra $\mathrm{X}$ chromosome may influence a better clinical outcome. Testicular atrophy did not protect from the development of infection. The presence of one affected cohabitant significantly associated with SARS-CoV-2 infection. An association between SARS-CoV-2 and hypogonadism was confirmed, whereas the formulation of TRT was irrelevant.

Acknowledgements This research was in part supported by the volunteer help of support Association "Nascere Klinefelter".

Author contribution Conceptualization: MRA; methodology: MRA; investigation: LA and IG; formal analysis: LA, IG, and SL; writingoriginal draft preparation: LA and MRA; writing - review and editing: LA, MV, SL, MB, MCZ, and MRA; supervision: MRA. All authors read and approved the final manuscript.

Funding This research was in part supported by funds of the University of Ferrara (FAR 2019, 2020), in cooperation with the LTTA of the University of Ferrara.

Data availability statement Data that support the findings of this study are available on request from the corresponding author. The data are not publicly available due to privacy or ethical restrictions. 
Code availability Not applicable.

\section{Declarations}

Conflict of interest All authors have no conflict of interest.

Informed consent Informed consent was obtained from all patients to be included in the study.

Human studies and ethics approval Approval to conduct this human subject research was obtained from the Local Ethic Committee. All procedures were in accordance with the ethical standards of the committee responsible for human experimentation (institutional and national) and with the 1964 Helsinki declaration and its later amendments or comparable ethical standards.

Animal studies This article does not contain any studies with animals carried out by any of the authors.

Consent for publication Patients signed informed consent regarding publishing their data.

\section{References}

1. Lipsky MS, Hung M (2020) Men and COVID-19: a pathophysiologic review. Am J Mens Health 14(5):1557988320954021. https://doi.org/10.1177/1557988320954021

2. Mikkonen L, Pihlajamaa P, Sahu B, Zhang FP, Janne OA (2010) Androgen receptor and androgen-dependent gene expression in lung. Mol Cell Endocrinol 317(1-2):14-24. https://doi.org/10. 1016/j.mce.2009.12.022

3. Sharifi N, Ryan CJ (2020) Androgen hazards with COVID-19. Endocr Relat Cancer 27(6):E1-E3. https://doi.org/10.1530/ ERC-20-0133
4. Rambhatla A, Bronkema CJ, Corsi N, Keeley J, Sood A, Affas Z, Dabaja AA, Rogers CG, Liroff SA, Abdollah F (2021) COVID-19 infection in men on testosterone replacement therapy. J Sex Med 18(1):215-218. https://doi.org/10.1016/j.jsxm.2020.09.013

5. Lanser L, Burkert FR, Thommes L, Egger A, Hoermann G, Kaser S, Pinggera GM, Anliker M, Griesmacher A, Weiss G, BellmannWeiler R (2021) Testosterone deficiency is a risk factor for severe COVID-19. Front Endocrinol (Lausanne) 12:694083. https://doi. org/10.3389/fendo.2021.694083

6. Barbagallo F, Calogero AE, Cannarella R, Condorelli RA, Mongioì LM, Aversa A, La Vignera S (2020) The testis in patients with COVID-19: virus reservoir or immunization resource. Transl Androl Urol 9(5):1897-1900. https://doi.org/10.21037/tau-20-900

7. Zitzmann M, Aksglaede L, Corona G, Isidori AM, Juul A, T'Sjoen G, Kliesch S, D’Hauwers K, Toppari J, Słowikowska-Hilczer J, Tüttelmann F, Ferlin A (2021) European academy of andrology guidelines on Klinefelter Syndrome endorsing organization: European society of endocrinology. Andrology 9(1):145-167. https:// doi.org/10.1111/andr.12909

8. Bassi F, Arbia G, Falorsi PD (2021) Observed and estimated prevalence of Covid-19 in Italy: How to estimate the total cases from medical swabs data. Sci Total Environ 764:142799. https:// doi.org/10.1016/j.scitotenv.2020.142799

9. Malmgren J, Guo B, Kaplan HG (2021) Continued proportional age shift of confirmed positive COVID-19 incidence over time to children and young adults: Washington State March-August 2020. PLoS ONE 16(3):e0243042. https://doi.org/10.1371/journal.pone

10. EpiCentro Coronavirus-news. https://www.epicentro.iss.it/coron avirus/aggiornamenti.

Publisher's Note Springer Nature remains neutral with regard to jurisdictional claims in published maps and institutional affiliations. 